\title{
Use and interpretation of phrases in histopathology reports
}

A histopathology report should provide a clinician with an accurate diagnosis and information helpful in the prognosis and patient management $[1,2]$. This information should be conveyed without ambiguity.

The pathologist is sometimes unable to arrive at a definite diagnosis because of inadequacy of clinical information, lack of ancillary investigations or the type of sample received. Pathologists use a variety of descriptive phrases to convey a level of diagnostic certainty when making a diagnosis. The clinicians' appreciation of the intended level of diagnostic certainty is important in patient management. Local audits have addressed the adequacy and completeness of reporting in malignancy $[1,2]$, but have failed to address this aspect. The aim of this study was to make a comparative assessment of the interpretation and use of common descriptive phrases used in pathology reports by clinicians and pathologists, and to determine whether there was a good understanding between the groups .

The most commonly used descriptive phrases were chosen from among 250 randomly selected reports from four departments (Table 1). The Concise Oxford Dictionary of Current English was used to assess how definitive these phrases were. Pathologists and clinicians were asked to score the level of diagnostic certainty on a scale of $0-5$ for each phrase. Zero denoted total diagnostic uncertainty and 5 total diagnostic certainty. The pathologists were categorised on their use of the phrases as frequent, occasional, and never; and clinicians were classed on their preference in two categories as like and dislike (confusing). The questionnaire was distributed to 15 pathologists in active practice and 15 clinicians of consultant grade.

The table shows the level of diagnostic certainty conveyed by the phrases, as interpreted by the pathologists and clinicians, and the number and percentage of clinicians who liked the phrase and the pathologists who frequently used the phrase. There was a wide variation in interpretation of phrases between pathologists and clinicians, except in a few phrases such as 'diagnostic of' and 'characteristic of', 'compatible with', and 'consistent with'. The last two phrases were thought to convey a high degree of certainty, despite the fact that they were semantically less definite.

The results show that the phrases used in pathology reports are interpreted differently by pathologists and clinicians, causing ambiguity. Furthermore, pathologists themselves differed in their opinion as to the diagnostic certainty of these phrases. This stresses the need for communication between pathologists and clinicians.

In cytological practice, this problem has been minimised by adopting a numerical reporting system [3] 
Table 1. Phrases and diagnostic certainty

\begin{tabular}{|c|c|c|c|c|c|c|c|c|}
\hline \multirow[t]{2}{*}{ Phrases } & \multirow{2}{*}{$\begin{array}{c}\text { Clinicians liking the phrase (\%) } \\
\text { and pathologists frequently } \\
\text { using the phrase (\%) }\end{array}$} & \multicolumn{7}{|c|}{ Level of diagnostic certainty } \\
\hline & & $\overline{0}$ & 1 & 2 & 3 & 4 & 5 & $\begin{array}{c}\text { No } \\
\text { response }\end{array}$ \\
\hline \multicolumn{9}{|c|}{ Phrases that are definitive } \\
\hline \multicolumn{9}{|l|}{ Diagnostic of } \\
\hline Clinicians & $11(33.3)$ & & & & & 2 & 11 & 2 \\
\hline Pathologists & $3(20.0)$ & & & & & & 12 & 3 \\
\hline \multicolumn{9}{|l|}{ Characteristic of } \\
\hline Clinicians & $10(66.7)$ & & & & & 8 & 5 & 2 \\
\hline Pathologists & $1(6.7)$ & & & & & 2 & 6 & 7 \\
\hline \multicolumn{9}{|l|}{ Indicative of } \\
\hline Clinicians & $7(46.7)$ & 2 & 2 & 5 & 4 & & & 2 \\
\hline Pathologists & $3(20.0)$ & & 2 & 4 & 3 & 1 & & 5 \\
\hline \multicolumn{9}{|l|}{ That / those of } \\
\hline Clinicians & $6(40.0)$ & 1 & & 2 & 2 & 3 & 6 & 1 \\
\hline Pathologists & $11(73.3)$ & & & & 1 & 1 & 9 & 4 \\
\hline \multicolumn{9}{|l|}{ Show / reveal } \\
\hline Clinicians & $6(40.0)$ & 1 & 1 & 4 & 1 & 5 & 3 & \\
\hline Pathologists & $7(46.7)$ & & & & 1 & 1 & 5 & 8 \\
\hline \multirow{2}{*}{\multicolumn{9}{|c|}{$\begin{array}{l}\text { Phrases that are } \\
\text { less definitive }\end{array}$}} \\
\hline & & & & & & & & \\
\hline \multicolumn{9}{|l|}{ Consistent with } \\
\hline Clinicians & $6(40.0)$ & & & & 4 & 4 & 7 & \\
\hline Pathologists & $11(73.3)$ & & & 2 & 8 & 5 & & \\
\hline \multicolumn{9}{|l|}{ Compatible with } \\
\hline Clinicians & $10(66.7)$ & & & 1 & 1 & 8 & 5 & \\
\hline Pathologists & $6(40.0)$ & & & 2 & 2 & 8 & 2 & 1 \\
\hline \multicolumn{9}{|l|}{ Suggestive of } \\
\hline Clinicians & $5(33.3)$ & 1 & & 1 & 10 & 1 & 1 & 1 \\
\hline Pathologists & $6(40.0)$ & 1 & 3 & 7 & 2 & & & 2 \\
\hline \multicolumn{9}{|l|}{ Suspicious of } \\
\hline Clinicians & $3(20.0)$ & & & 2 & 4 & 6 & 1 & 2 \\
\hline Pathologists & $0(0.0)$ & & & & 2 & 2 & 3 & 8 \\
\hline \multicolumn{9}{|l|}{ Reminiscent of } \\
\hline Clinicians & $3(20.0)$ & 2 & 3 & 4 & 2 & & & 4 \\
\hline Pathologists & $0(0.0)$ & & & 3 & 1 & 2 & & 9 \\
\hline \multicolumn{9}{|l|}{ In favor of } \\
\hline Clinicians & $1(6.6)$ & & 1 & 1 & 5 & 4 & 1 & 3 \\
\hline Pathologists & $0(0.0)$ & & & 1 & 6 & 4 & & 4 \\
\hline \multicolumn{9}{|l|}{ In keeping with } \\
\hline Clinicians & $4(26.7)$ & & 2 & 2 & 2 & 7 & 2 & \\
\hline Pathologists & $6(40.0)$ & & & & & 6 & 6 & 3 \\
\hline
\end{tabular}

Pathologists should try to convey their degree of diagnostic certainty as clearly as the written word can. It may be useful to qualify less definitive diagnoses with suggestions of steps required to strengthen the diagnosis. There is a need to establish clear guidelines regarding the use and interpretation of phrases in pathologists' reports.

\section{References}

1. De Silva MVC, Kumarasinghe MP, Histopathology reports of malignant tumours: are guidelines necessary? Journal of Diagnostic Pathology 2000; 1:1-2.

2. Hewavisenthi SJDeS, Samarasekera DS, Priyadharshani JWS. Colorectal carcinoma - audit of histopathology reports. Journal of Diagnostic Pathology 2000; 1: 19-22

3. Department of Health and Royal College of Pathologist Working Group. Pathology Reporting in Breast Cancer Screening. 2nd ed. London: Royal College of Pathologist, 1997.

SJ De S Hewavisenthi, Senior Lecturer, Department of Pathology, Faculty of Medicine, University of Kelaniya, and Pradeep Fernando, Orthopaedic Surgeon, North Colombo Teaching Hospital, Sri Lanka.

Correspondence: SJ de SW, e-mail: <prajafer@mail.ewisl.net> (Competing interests: none declared). Received 1 May and revised version accepted 1 July 2004. 